\title{
Differences in the Modal and Structural Parameters of Resonance and Non-Resonance Wood of Spruce (Picea abies L.)
}

\author{
P. MANIA ${ }^{a}$, E. FABISIAK ${ }^{a}$ AND E. SKRODZKA ${ }^{b}$ \\ ${ }^{a}$ Department of Wood Science, Poznań University of Life Sciences, Wojska Polskiego 38/42, 60-627 Poznań, Poland \\ ${ }^{b}$ Faculty of String Instruments, Harp, Guitar and Violin-Making, I.J. Paderewski Academy of Music, \\ św. Marcin 87, 61-808 Poznań, Poland
}

\begin{abstract}
Results of modal analysis and evaluation of cyclic inhomogeneity of wood and cell wall ultrastructure of a resonance and non-resonance spruce wood (Picea abies L.) are presented. The resonance wood came from a tree from Istebna, while the non-resonance wood came from a tree from the vicinity of Olsztyn. Modal analysis was made by a pulse excitation. The resonance and non-resonance wood differ in the fundamental modal parameters as well as in the number of vibrational modes. Macrostructural parameters of the wood samples were also measured. The angles of cellulose microfibrils in tangent walls of tracheids (microfibril angles or MFA) within individual annual rings were measured. The resonance wood was found to show high cyclic homogeneity of macro- and ultrastructural features.
\end{abstract}

DOI: 10.12693 /APhysPolA.127.110

PACS: $43.20 . \mathrm{Ks}, 83.80 . \mathrm{Mc}$

\section{Introduction}

In recent years much attention has been paid to analysis of the properties of wood that could determine its suitability for particular applications. A general definition of wood quality is difficult as different applications demand different wood features. String musical instruments are built of a few species of wood, however, the top plates of the resonance body are usually made of spruce. Many authors have analysed the properties of resonance wood, however still there are no generally accepted criteria allowing evaluation of its suitability for construction of musical instruments [1, 2]. Visual classification of resonance wood by string instrument makers is based mainly on macroscopic features such as the width of annual rings and contribution of latewood, which are not fully informative on the actual quality of wood. Although many attempts have been made to define other criteria of wood quality such as physico-mechanical properties or acoustic parameters, no definite solution to the problem has been found.

A very important feature influencing the quality of resonance wood is the ultrastructure of cell walls. For the use in musical instruments, the wood should have the ultrastructure with very small microfibril angles (MFA) in S2 layer of cellular wall, almost parallel to the longitudinal axis of the cell. With decreasing MFA, the velocity of acoustic wave propagation in wood increases [3].

Vibrational properties are often described in terms of modal parameters [4-7]. A mode of vibration is a global property of a structure and it corresponds to a particular modal frequency. The motion of all points at the same time is described by a mode shape. The second modal parameter is modal damping, depending on the shape of an object, material constants and constraints. Therefore, modal analysis permits determination of all modes of vibration by specification of the modal frequency, modal damping and mode envelope. These parameters depend on the structure of the wood and are important for evaluation of wood for production of musical instruments. As follows from literature, it is not always possible to achieve the agreement between the above-mentioned parameters for unambiguous evaluation of the resonance wood quality [8]. Therefore, an alternative solution is the search for correlations between the parameters describing the wood structure on the macro-, micro- and submicroscopic levels and the vibrational parameters of wood.

\section{Material and methods}

The study was performed for a spruce wedge classified by luthiers as good resonance wood, mainly on the basis of macroscopic features such as the width of annual rings and contribution of latewood. The spruce tree from which the sample was taken grew near Istebna, in Beskid Ślaski, which is the region well known of the best wood for musical instruments. The control wood from a tree grown near Olsztyn did not show the features of resonance wood. Modal analysis was performed on samples $260 \mathrm{~mm}$ (in longitudinal direction) $\times 120 \mathrm{~mm}$ (in radial direction) $\times 16 \mathrm{~mm}$ (in tangential direction) with 171 measuring points equally distant $(14 \mathrm{~mm} \times 14 \mathrm{~mm})$ (Fig. 1).

An experimental modal analysis with a fixed response point and varied excitation point was the experimental tool used. The response signal was measured by an Ono Sokki accelerometer NP-2910, of $2 \mathrm{~g}$ in mass, attached on bee wax. The sample was excited by an impact hammer with a piezoelectric force transducer (PCB Piezoelectron- 
260

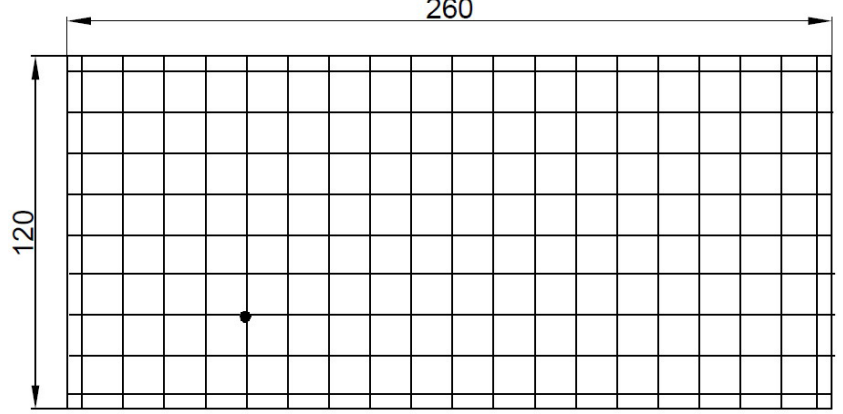

Fig. 1. Measuring points for modal analysis of a wood sample and the site of accelerometer attachment - a black dot.

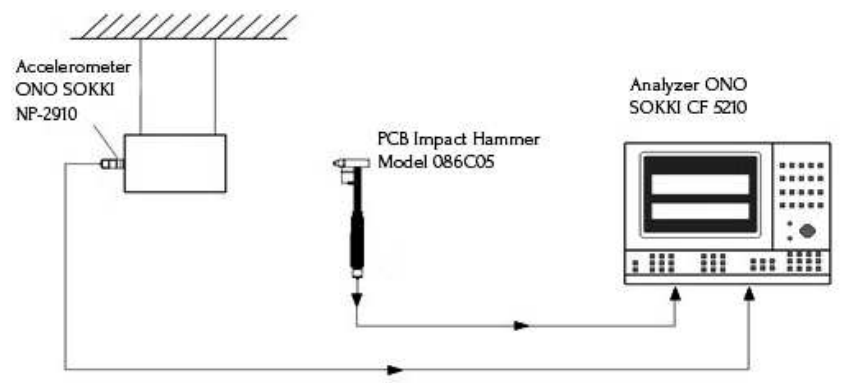

Fig. 2. Diagram of the measurement system to modal testing.

ics Impact Hammer Model 086C05). The accelerometer and impact hammer were connected to ONO SOKKI analyser CF 5210 (Fig. 2). The modal parameters were calculated using the software packet SMS STAR Modal. Measurements were made for the frequencies $0-6000 \mathrm{~Hz}$ with the spectral resolution of $3 \mathrm{~Hz}$.

Ten spectral averages were used to improve signal-tonoise ratio. Each measurement was controlled by the coherence function. The wood moisture content was $9 \%$.

Macrostructural parameters and MFA were measured by a computer image analyzer using the program Motic Images Plus 2.0. The microscopic sections for MFA measurements (in S2 layer of tangent walls of tracheids), taken from early and latewood selected annual rings of about $20 \mu \mathrm{m}$ in thickness, were sliced by a sledge microtome. To visualise the position of cellulose fibrils, the sections were heated in a solution of copper nitrate $\mathrm{Cu}\left(\mathrm{NO}_{3}\right)_{2} \cdot 3 \mathrm{H}_{2} \mathrm{O}$ at $90^{\circ} \mathrm{C}$ for $28 \mathrm{~h}[9,10]$.

\section{Results}

In Table I the values of modal frequency $f$, percentage of critical modal damping $d$ and the width of the resonance maximum $D$ obtained for the resonance and the non-resonance spruce wood are presented, for the most distinct and characteristic modes obtained in the studied frequency range. An important criterion was damping, less than $10 \%$ of critical damping, as only objects of damping lower than $10 \%$ can be classified as linear [5]. The modes of critical damping higher than $10 \%$ were marked by italic fonts (Table I).

TABLE I

Modal parameters obtained by impact excitation for wood of different origin $(f-$ modal frequency, $d-$ modal damping, $D$ - width of the resonance maximum).

\begin{tabular}{c|c|c|c|c|c|c}
\hline \hline \multirow{2}{*}{$\begin{array}{c}\text { Mode } \\
\text { no. }\end{array}$} & \multicolumn{3}{|c|}{ Resonance wood } & \multicolumn{3}{c}{ Non-resonance wood } \\
\cline { 2 - 7 } & $f[\mathrm{~Hz}]$ & $d[\%]$ & $D[\mathrm{~Hz}]$ & $f[\mathrm{~Hz}]$ & $d[\%]$ & $D[\mathrm{~Hz}]$ \\
\hline 1 & 324 & 8.51 & 53.3 & 375 & 28.09 & 80.2 \\
2 & 630 & 9.19 & 71.0 & 839 & 20.81 & 178.5 \\
3 & 1373 & 9.52 & 131.1 & - & - & - \\
4 & 1671 & 7.09 & 119.0 & - & - & - \\
5 & 2229 & 6.23 & 138.8 & - & - & - \\
6 & 2872 & 4.46 & 134.9 & - & - & - \\
7 & 3512 & 2.44 & 84.0 & 3376 & 1.93 & 64.8 \\
8 & 3793 & 4.84 & 183.7 & 3693 & 3.30 & 121.9 \\
9 & 4016 & 2.70 & 114.8 & 4040 & 6.07 & 271.0 \\
10 & 4920 & 5.69 & 280.2 & 4823 & 2.91 & 154.2 \\
11 & 5474 & 4.40 & 240.6 & 5428 & 2.79 & 156.7 \\
12 & 5912 & 2.75 & 162.3 & 5624 & 2.21 & 130.5
\end{tabular}

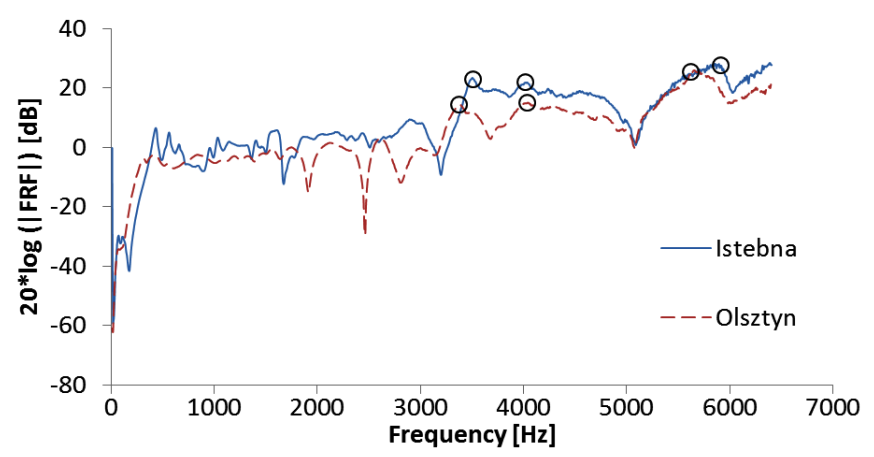

Fig. 3. The frequency response function for the resonance wood from Istebna and control wood from Olsztyn.

From Table I it is clear that the number of modes was not the same for both spruce samples. In the control wood, no modes of frequencies $1000-3000 \mathrm{~Hz}$ were found. At very low frequencies the modes were characterised by high damping values, close to $30 \%$ of the critical damping. In the wood from Istebna, the low-frequency modes 1 and 2, were identified. Their critical damping was close to $10 \%$, but not higher than this value. Further analysis was performed for the modes 7,9 and 12 as these were the first modes present in both types of wood, showing critical damping below $10 \%$. For both samples of wood, the mode envelopes had similar shapes.

Figure 3 presents the frequency response function (FRF) for the resonance and control wood samples. The points indicating the positions of the modes analysed are marked by circles. The modal frequencies determined for each sample do not coincide and the plots for particular 
samples are significantly mutually shifted. The vibrations in the resonance wood have much greater amplitudes than those in the control wood, which means that the resonance wood is more apt to free vibrations. The first analyzed mode 7 had two nodal lines perpendicular to the longer axis of the sample. Its modal frequencies were $3512 \pm 3 \mathrm{~Hz}$ for the resonance wood and $3376 \pm 3 \mathrm{~Hz}$ for the control sample. The mode labelled by 9 , of a high frequency, was characterised by three nodal lines along the longer axis of the sample. For the two studied samples of wood the frequencies of this mode were similar and close to $4 \mathrm{kHz}$. Mode 12 occurred at a high frequency of almost $6 \mathrm{kHz}$. The envelope of this mode showed three nodal lines perpendicular to the longer axis of the sample. For all analysed modes (except for 9.) the modal frequencies of the resonance wood were higher than those of the control wood sample. The differences in the modal parameters are to a high degree related to the differences in the structure of the wood tissues compared. Therefore, another element of the comparative analysis of the two wood samples of different origin was determination of parameters of their macrostructure, which describe the inhomogeneity of wood tissues and significantly influence the resonance properties of wood.

Statistical data characterising the above-mentioned parameters are given in Table II. The mean widths of annual rings in the two samples were comparable and equal to $1.41 \mathrm{~mm}$ and $1.53 \mathrm{~mm}$. Significant differences were found in the widths of latewood sections and its contribution in annual rings. This observation was confirmed by analysis of variance Anova. The test statistics $F=36.286$ for the widths of latewood zones, $F=45.666$ for the contribution of latewood, while the critical value is $F_{0.05: 1: 161}=3.890$. A comparison of the parameters determined for the resonance Istebna wood with the results presented by Spycher et al. [2] obtained for the resonance spruce wood classified by instrument makers as good/very good, indicates that the wood sample we studied could also be classified as good resonance wood. The wood from Istebna had very similar mean widths of annual rings and latewood contribution as the wood studied by Spycher et al. [2]. In the control wood the mean width of annual rings was similar to that in the resonance wood but the contribution of latewood and variation in this parameter were over 1.5 times greater than in the resonance wood.

In the wood tissues compared large differences were found in the ultrastructure of cell walls. The MFA values measured with respect to the longitudinal axis of tracheids in the resonance and control samples are shown in Table III. These are mean values calculated on the basis of the measurements for a few preparations sliced from latewood and earlywood sections. The mean MFA for entire annual rings in the resonance wood was $3.9^{\circ}$ and by about 3 times lower than in the control sample in which it was $11.7^{\circ}$. In the control sample the differences between the highest and the smallest mean value MFA in early and latewood were the most pronounced.
TABLE II

Statistical characteristics of latewood zones width (L), annual rings width $(\mathrm{R})$ and percentage of latewood (PL) for resonance and non-resonance wood $( \pm S-$ stand. deviation, $V$ - coefficient variation).

\begin{tabular}{l|c|c|c|c|c}
\hline \hline \multirow{2}{*}{} & \multicolumn{5}{|c}{ Basic statistical parameters } \\
\cline { 2 - 4 } & Mean & Min & Max & $\pm S$ & $V$ \\
\cline { 2 - 5 } & \multicolumn{5}{|c}{ [m] } \\
\cline { 2 - 5 } & \multicolumn{5}{|c}{ Resonance wood } \\
\hline L & 0.28 & 0.04 & 0.59 & 0.127 & 45.6 \\
R & 1.41 & 0.45 & 2.63 & 0.457 & 32.5 \\
PL & 19.51 & 3.48 & 39.25 & 6.757 & 34.6 \\
\hline & 0.42 & 0.12 & 0.93 & 0.182 & 43.4 \\
\hline L & 1.53 & 0.51 & 4.21 & 0.677 & 44.2 \\
R & 30.89 & 6.57 & 59.36 & 13.89 & 45.0 \\
PL & \multicolumn{5}{|c}{ Non-resonance wood } \\
\end{tabular}

TABLE III

Statistical characteristics of MFA of tracheids in early (E) and late (L) zones of annual rings resonance and nonresonance spruce wood.

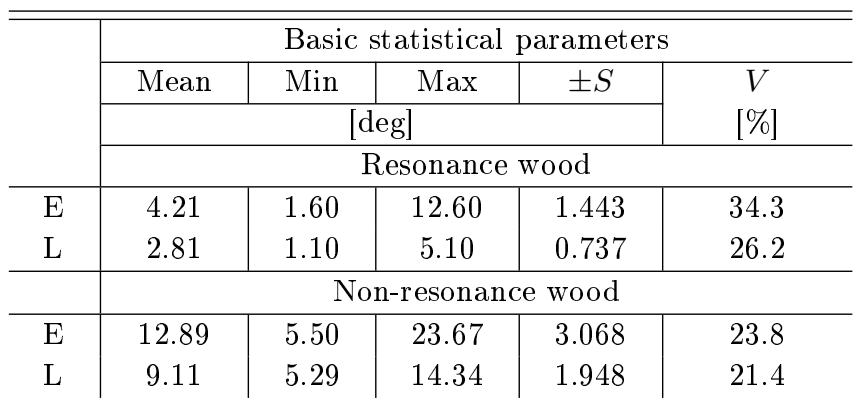

\section{Conclusions}

1. In the resonance and control wood the number of modes was not the same in the measured frequency range. In the control sample no modes were found in the range of low frequencies (1000$3000 \mathrm{~Hz}$ ), while in the resonance wood four characteristic modes were noted. The amplitudes of vibrations in the resonance wood were greater than in the control sample, which means that the resonance wood is more apt to free vibrations. The resonance frequencies of the wood from Istebna were higher than those in the control sample.

2. The mean widths of annual rings in the resonance wood and control wood were similar and equal to $1.41 \mathrm{~mm}$ and $1.51 \mathrm{~mm}$, respectively, but the contribution of latewood in control wood were over 1.5 times greater than in the resonance wood. Mean value of MFA in the resonance wood was near $3.9^{\circ}$ so three times lower than that of the control sample $\left(11.7^{\circ}\right)$. Thus, the macrostructure and the ultrastructure of the resonance wood was more uniform than that of the control wood. 
3. The higher values of modal parameters for the resonance wood were a result of greater uniformity of its structure and therefore its higher quality.

\section{References}

[1] C. Buksnowitz, A. Teischinger, U. Müller, A. Pahler, R. Evans, J. Acoust. Soc. Am. 121, 2384 (2007).

[2] M. Spycher, F.W.M.R. Schwarze, R. Steiger, Wood Sci. Technol. 42, 325 (2008).

[3] E. Fabisiak, I. Čunderlik, W. Moliński, Ann. WULS - SGGW for Wood Technol. 71, 170 (2010).

[4] K.D. Marshall, J. Acoust. Soc. Am. 77, 695 (1985).
[5] E. Skrodzka, A. Krupa, E. Rosenfeld, B.J. Linde, Appl. Opt. 48, C165 (2009).

[6] E. Skrodzka, A. Łapa, B.B.J. Linde, E. Rosenfeld, J. Acoust. Soc. Am. 130, 2186 (2011).

[7] T. Ono, M. Norimoto, Rheol. Acta 23, 652 (1984).

[8] R. Hori, M. Müller, U. Watanabe, H. Lichtenegger, P. Fratzl, J. Sugiyama, J. Mater. Sci. 37, 4279 (2002).

[9] H.H. Wang, J.G. Drummond, S.M. Reath, K. Hunt, P.A. Watson, Wood Sci. Technol. 34, 493 (2001).

[10] E. Fabisiak, W. Moliński, M. Cisowski, in: Wood Structure and Properties, Arbora Publ., Zvolen 2007, p. 39 . 